\title{
Effect of Chemical Oxidation on the Adsorption Properties of Cationic Dye on Activated Carbons Prepared from Locally Atropa belladonna
}

\author{
Wafaa E. Rashwan*, Thoria El-Nabarawy, Reham M. Aboelenein and Nady A. \\ Fathy \\ Physical Chemistry Department, National Research Centre, Dokki, Cairo, Egypt.
}

\begin{abstract}
$\mathbf{T}$ HIS STUDY investigates the influence of wet chemical oxidation using nitric acid and ammonium persulfate on the surface nature and the adsorption properties of activated carbon prepared from sulfuric acid activation of locally Atropa belladonna plant at $200^{\circ} \mathrm{C}$. The surface properties of produced carbons (AC-S, AC-S/N and AC-S/A, respectively) were demonstrated by FTIR, potentiometric titration and $\mathrm{N}_{2}$ adsorption. The adsorption properties of these carbons were estimated using methyl green (MG) dye as a cationic dye. The effect of variables including $\mathrm{pH}$, initial dye concentration and contact time on the adsorption properties of these carbons was studied. Acidic carbon adsorbents were obtained with large content of acidic surface functional groups in the sequence order $\mathrm{AC}-\mathrm{S}<\mathrm{AC}-\mathrm{S} / \mathrm{N}<\mathrm{AC}-\mathrm{S} / \mathrm{A}$ as confirmed by FTIR and potentiometric plots. It was assessed that a large number of basic functional groups were generated after oxidation with ammonium persulfate $(\mathrm{AC}-\mathrm{S} / \mathrm{N})$ and hence led to a decrease in its adsorption capacity towards MG dye. High adsorption capacities were found to be 100,200 and $125 \mathrm{mg} / \mathrm{g}$ from MG dye onto AC-S, AC-S/N and AC-S/A, respectively. The adsorption results show that the adsorption was $\mathrm{pH}$ dependent with a high adsorption at $\mathrm{pH}$ of 6 which is obviously $\mathrm{pH}$ of dye solution. The equilibrium adsorption data were analyzed by Langmuir, Freundlich and Florry-Huggins' isotherm models. Pseudo-second-order kinetic model and Langmuir isotherm model showed better fit to the adsorption of MG dye onto the prepared carbons. Overall, this study reveals that the obtained carbons from Atropa belladonna are effective adsorbents in removing dyes from wastewater sources. Finally, the results also suggest that oxidation treatment with nitric acid is more efficient than ammonium persulfate to produce high acidic carbon adsorbents.
\end{abstract}

Keywords: Atropa belladonna biomass, Activated carbons, Wet oxidation, Acid-base character, Liquid phase adsorption, Methyl green dye.

\section{Introduction}

Activated carbons (ACs) are very vital porous materials due to their extensive surface area, microporous character and their surface chemical nature. Such properties have made them potentials as adsorbents, electronic material, catalyst/catalyst supports and energy storage. Particularly, ACs adsorption processes are considered as the best available technology (BAT) for the removal of industrial pollutants including heavy metals, organics, pesticides, dyes, solvents and also fuel hydrocarbons from drinking water $[1,2]$. Generally, the adsorption capacity of ACs significantly depended on their surface chemistry and is largely influenced by both quantity and type of the surface functional groups. Accordingly, many studies have considerable interests in the improvement of the surface chemistry properties of ACs via chemical oxidation and reported their relations with the adsorption of dyes and heavy metals in the last two decades [3-13].

The surface chemistry of carbon materials demonstrates their acid-base character, catalytic properties, moisture content and adsorption properties. This is due to the presence of heteroatoms attached with carbon atoms within the carbon matrix. The most common heteroatoms are oxygen, nitrogen, phosphorous,

*Corresponding author e-mail: wafaae.rashwan@yahoo.com

DOI: 10.21608/EJCHEM.2018.2954.1259

(C)2017 National Information and Documentation Center (NIDOC) 
sulfur, ...etc. They are present on the surface and bound to the edges of the graphite-like layers and form the organic functional groups such as phenols, carboxylic acids, lactones, aldehydes, ethers, carbonyls, nitro compounds, amines and phosphates $[4,9,11]$. The nature of these functional groups is mainly being acidic, basic or neutral, which can be employed by wet or dry oxidation and quantified by potentiometric or Boehm's titration and temperature-programmed desorption (TPD) [9, 11, 14]. For example, the acidic character of activated carbons is chiefly attributed to surface oxygen groups such as phenol, carboxylic acid, lactone, and lactol groups (Fig. 1) that are situated at the edges of the polyaromatic basal plane sheets as identified by Fuente et al. [15]. Whereas, the basic character of activated carbons arises from the presence of basic oxygen-containing functional groups (e.g. chromene, pyrone, quinone or diketone groups), delocalized $\pi$-electrons of the polyaromatic sheets (e.g. C $\pi$ basal planes), nitrogen-containing surface functional groups (e.g. pyridinic groups) and/or inorganic impurities (metal oxides). Such functional groups can be introduced into the matrix of ACs by means of liquid phase treatments, using $\mathrm{H}_{2} \mathrm{O}_{2}$ or $\mathrm{HNO}_{3}$ at different concentrations, temperatures, times, or by gas phase oxidation with air; $\mathrm{O}_{2}$ or $\mathrm{N}_{2} \mathrm{O}$ at different temperatures, concentrations, pressures and/or contact times; and by heat treatments at different temperatures to remove some of the acidic functional groups to form basic sites [3]. To prepare acidic carbons, $\mathrm{HNO}_{3}$ and ammonium persulfate $\left[\left(\mathrm{NH}_{4}\right)_{2} \mathrm{~S}_{2} \mathrm{O}_{8}\right]$ oxidizing agents are used extensively in the literature, in which they introduce mainly more carboxylic groups $\left(\mathrm{COO}^{-}\right)$at the surface of $\mathrm{ACs}$ $[3-5,10-16]$.

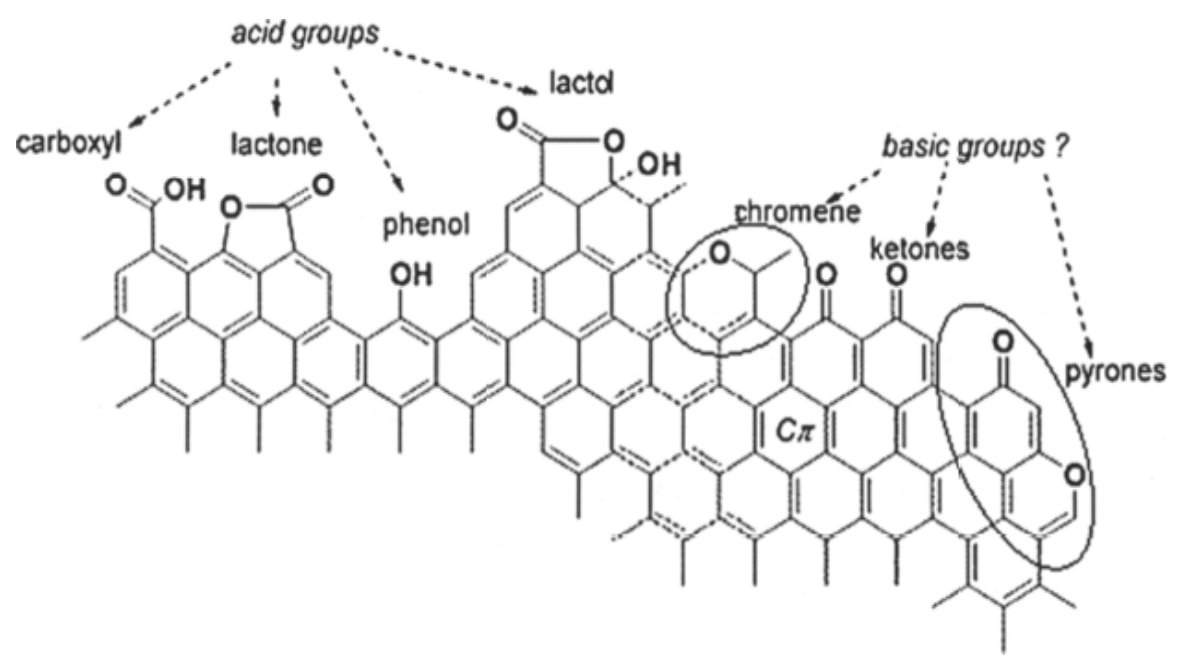

Fig. 1. Suggested acidic and basic oxygen-containing functional groups on activated carbon surfaces; $\mathrm{C} \boldsymbol{\pi}$ indicates that basicity may also be associated with delocalized $\pi$ electrons on the polyaromatic basal plane as reported by Fuente et al. [15].

Activated carbons can be prepared from various carbon feedstocks including biomass, e.g. coconut shells, wood, peat, coal and charcoal and synthetic polymers as nylon, rubber, poly acrylonitrile, etc. Their final surface properties depend on the activation method, time of activation as well as oxidation process. Chemical activation of carbon feedstocks with $\mathrm{H}_{3} \mathrm{PO}_{4}[3,6] \mathrm{KOH}[5]$ and $\mathrm{H}_{2} \mathrm{SO}_{4}[17,18]$ has attracted much attention because it causes strong polymerization through activation process. In this respect, it is substantial in the production of ACs to select low-cost raw materials that are rich in carbon content. Hence, a potential beneficial use for the Atropa belladonna (commonly known as belladonna) as feedstock of ACs production is recommended in this study. It is a herbaceous plant, which is abundantly found throughout the year in Egypt and many countries in the world. It has a lengthy history of use as medicine, poison, cosmetic also as an anesthetic for surgery [19]. Based on a literature review of the last fifty years, we note that there are no studies have examined the preparation of activated carbons from this lignocellusoic material, belladonna. In this study, we have been examined the feasibility of producing activated carbon from belladonna. To maximize its adsorption capacity, the chemical activation of Atropa belladonna 
with sulfuric acid and then followed by chemical oxidation with $\mathrm{HNO}_{3}$ or $\left(\mathrm{NH}_{4}\right)_{2} \mathrm{~S}_{2} \mathrm{O}_{8}$ was carried out in the present study.

The use of activated carbons (ACs) in water plants represents a typical technology for removing numerous pollutants. In addition, the remediation of wastewater sources contaminated by xenobiotic color organics is very required in issues of global environmental pollution to minimize their concentration and to recycle this water in further industrial or agricultural purposes. More than 1,00,000 kinds of dyes are available commercially, with over $7 \times 10^{5}$ tons of dyestuff that are produced annually. Dyestuff can be categorized based on their structure as anionic and cationic [20]. In aqueous solution, anionic dyes carry a net negative charge as a result of the presence of sulphonate $\left(\mathrm{SO}^{3-}\right)$ groups. On the other hand, cationic dyes have a net positive charge due to the presence of sulfur containing groups or protonated amine [21]. Discharging dyes into the hydrosphere can result in environmental sever damage because the dyes give water undesirable color and taste besides they decrease sunlight penetration, with some dyes that are toxic/ carcinogenic [20-25].

In this study, the adsorption capacity of the prepared carbons from belladonna was determined through adsorption of methyl green dye ( $\mathrm{MG}$, cationic dye) from aqueous solution with analyzing the adsorption data by Langmuir, Freundlich and Florry-Huggins. The mechanism of adsorption was also expected and estimated using adsorption kinetic models such as pseudo-first-order, pseudo-second-order besides intraparticle diffusion models. Finally, the purpose of this work is to study the influence of wet chemical oxidation using acid solutions such as nitric and ammonium persulfate on the chemical surface and adsorption properties of chemically activated carbon produced from activation of belladonna with sulfuric acid at low temperature $200^{\circ} \mathrm{C}$. The resulting samples were characterized by FTIR, potentiometric titration and $\mathrm{N}_{2}$ adsorption. The variables including $\mathrm{pH}$, initial dye concentration, contact time in addition to the adsorption properties of these carbons were studied using methyl green dye as a cationic dye. Batch studies for adsorption of $\mathrm{MG}$ onto the prepared carbons (equilibrium and kinetic studies) were also investigated at the optimum $\mathrm{pH}$.

\section{Experimental}

Materials

Natural plant of belladonna was collected from the garden of the National Research Center (NRC), Cairo, Egypt. Sulfuric acid $\left(\mathrm{H}_{2} \mathrm{SO}_{4}, 98 \%\right)$, Nitric acid $\left(\mathrm{HNO}_{3}, 69 \%\right)$ were purchased from Riedelde Haën. Ammonium persulfate $\left(\left(\mathrm{NH}_{4}\right)_{2} \mathrm{~S}_{2} \mathrm{O}_{8}\right.$, $228.19 \mathrm{~g} / \mathrm{mol}, 98 \%$ ) was obtained from Panreac. Methyl green dye as indicator for cationic dye from aqueous solution was obtained from Sigma-Aldrich. Its chemical formula is shown in Fig. 2 (CAS Number: 7114-03-6, Formula: $\mathrm{C}_{27} \mathrm{H}_{35}$ $\mathrm{BrClN}_{3} \mathrm{ZnCl}_{2}$, Molecular Weight: $653.24 \mathrm{~g} / \mathrm{mol}$ ).<smiles></smiles>

Fig. 2. Chemical formula of methyl green dye.

\section{Preparation of activated carbons}

The collected Belladonna was washed thoroughly with distilled water to remove any undesirable wastes. The roots, stems and leaves of belladonna were cut out from the plant and dried at $80^{\circ} \mathrm{C}$ until dry weight was constant. Subsequently, these parts were milled using home-made mixer and the resulting particles were screened using ASTM standard sieves. The fractions with particle size between 0.3 and $0.5 \mathrm{~mm}$ were used to prepare activated carbons.

The crushed belladonna was treated with 50 $\mathrm{v} / \mathrm{v} \%$ of $\mathrm{H}_{2} \mathrm{SO}_{4}$ acid and left together overnight until soaked completely and then heated at $200^{\circ} \mathrm{C}$ for $4 \mathrm{~h}$. The resulting black sample was washed thoroughly with hot water and distilled water till $\mathrm{pH}$ of filtrate becomes neutral and then dried at $80^{\circ} \mathrm{C}$ overnight. This sample was assigned as AC-S. This sample was exposed to further wet chemical oxidation in the presence of acid solution either $\mathrm{HNO}_{3}$ or $\left(\mathrm{NH}_{4}\right)_{2} \mathrm{~S}_{2} \mathrm{O}_{8}$. For nitric oxidation, a portion of AC-S sample was mixed with $70 \mathrm{v} / \mathrm{v} \% \mathrm{HNO}_{3}$ and left till wetting at room temperature and then heated at $80^{\circ} \mathrm{C}$ for $3 \mathrm{~h}$. Then, the treated AC-S was separated from residual acid solution, washed with hot distilled water for several times and then dried at $80^{\circ} \mathrm{C}$ overnight. The product was denoted as AC-S/N. 
To prepare activated carbon oxidized with $\left(\mathrm{NH}_{4}\right)_{2} \mathrm{~S}_{2} \mathrm{O}_{8}$, a solution of ammonium persulfate in $2 \mathrm{M} \mathrm{H}_{2} \mathrm{SO}_{4}$ acid was added to known amount of AC-S sample and left overnight at room temperature. The mixture was refluxed at $110^{\circ} \mathrm{C}$ until no further $\mathrm{SO}_{2}$ gas was evolved. Afterward, the black solid was separated from residual acid solution, washed with hot distilled water for several times and then dried at $80^{\circ} \mathrm{C}$ overnight. The resulting product was denoted as AC-S/A.

\section{Characterization tools}

The slurry or surface $\mathrm{pH}$ values of the finely powdered activated carbons were measured by contacting $0.1 \mathrm{~g}$ of each sample with $25 \mathrm{~mL}$ distilled water in closed flask, under stirring at $80^{\circ} \mathrm{C}$ for $10 \mathrm{~min}$, allowing it to cool and recorded the supernatant $\mathrm{pH}$ liquid using a $\mathrm{pH}$ meter (HANNA pH20).

The nature of oxygen surface functional groups formed on the surface of activated carbons was investigated by Fourier Transform Infrared (FTIR) spectroscopy in the range of 4000-400 $\mathrm{cm}^{-1}$ using a JASCO 6100 FT-IR spectrometer, and the $\mathrm{KBr}$ disc technique.

Moreover, potentiometric titration has been a convenient analysis method of surface chemistry of activated carbon through determining surface charge $[8,9]$. Thus, the total amount of each acidic and basic surface groups introduced into surface of activated carbon was evaluated by the potentiometric titration method. This method was done using a DMS Titrino 848 automatic titrator (Metrohm, Brinkmann Instruments, Westbury, NY, USA). The instrument was set in the equilibrium mode when the $\mathrm{pH}$ was collected. Approximately $0.1 \mathrm{~g}$ samples were placed in a beaker with $25 \mathrm{~mL}$ of $0.5 \mathrm{~mol} / \mathrm{L} \mathrm{KCl}$ ) solution at $25^{\circ} \mathrm{C}$ and stirred for $10 \mathrm{~min}$. Each sample was titrated with $\sim 0.01 \mathrm{~mol} / \mathrm{L} \mathrm{KOH}$ titrant with 0.001 $\mathrm{mL}$ increments. These experiments were carried out in the $\mathrm{pH}$ range $4-11[8,9]$.

Evaluation of porous characteristics was carried out using nitrogen adsorption-desorption analysis at $-196^{\circ} \mathrm{C}$ (BEL-Sorp, Microtrac Bel Crop, Japan). The adsorption data were analyzed by applying several established procedures in order to get various texture characteristics of the adsorbents under consideration as follows: (i) surface area by the BET-method $\left(\mathrm{S}_{\mathrm{BET}}, \mathrm{m}^{2} / \mathrm{g}\right)$, and the total pore volume $\left(\mathrm{V}_{\mathrm{p}}, \mathrm{cm}^{3} / \mathrm{g}\right)$ from the volume adsorbed at a relative pressure of 0.95 . An estimate for the average pore diameter was calculated by $\bar{r}(\AA)=4 \mathrm{~V}_{\mathrm{p}} / \mathrm{S}_{\mathrm{BET}} \times 10^{4}[26,27]$.

\section{Adsorption studies}

Adsorption of methyl green as a cationic dye (MG) onto the oxidized carbon fiber samples was carried out in batch experiments at room temperature $\left(25^{\circ} \mathrm{C}\right)$. The influence of the solution $\mathrm{pH}$ on the adsorption of methyl green onto the activated carbons was performed at constant initial concentration of $150 \mathrm{mg} / \mathrm{L}$ of $\mathrm{MG}$ and the amount of adsorbent $(100 \mathrm{mg})$ under shaking for $4 \mathrm{~h}$ at $200 \mathrm{rpm}$ agitation speed and at $25^{\circ} \mathrm{C}$. To study the effect of dye initial concentration, different initial concentrations of MG (50-250 $\mathrm{mg} / \mathrm{L}$ ) were prepared and mixed with $100 \mathrm{mg}$ of prepared sample to carry out adsorption under magnetic stirring at $200 \mathrm{rpm}$ for $24 \mathrm{~h}$ in order to ensure the occurrence of equilibrium. Kinetic experiments were employed using a weight of 100 $\mathrm{mg}$ of activated carbons, which were added to a $250 \mathrm{~mL}$-conical flask containing $100 \mathrm{~mL}$ of $\mathrm{MG}$ solution with a fixed concentration at $100 \mathrm{mg} / \mathrm{L}$ upon stirring at a speed of $200 \mathrm{rpm}$ and $25^{\circ} \mathrm{C}$. This was followed by withdrawing aliquots of $0.2 \mathrm{~mL}$ at each interval time (10-100 $\mathrm{min})$, diluted and filtered through Whatman filter paper No. 41 to measure its final concentration.

To determine the adsorption capacity of prepared activated carbons, liquid-phase batch adsorption studies towards cationic dye were considered as follows. In each adsorption experiment, $50 \mathrm{~mL}$ of MG solutions with initial concentrations ranging from 20 to $200 \mathrm{mg} / \mathrm{L}$ were added into a set of $50 \mathrm{~mL}$ conical flasks and conducted with $50 \mathrm{mg}$ solid adsorbent at the optimum $\mathrm{pH}$ of $\mathrm{MG}$ solution. The flasks were kept in a shaker for $24 \mathrm{~h}$ at a speed of $200 \mathrm{rpm}$ and $25^{\circ} \mathrm{C}$. The MG solutions were separated from the adsorbent by filtration. Subsequently, the absorbance of the remaining concentration of $\mathrm{MG}$ in the aqueous solution was measured at wavelength of $530 \mathrm{~nm}$ using UV-vis spectrophotometer (Shimadzu-PC 2401).

The amount of MG adsorbed onto oxidized carbon fiber adsorbents at equilibrium $\left(q_{e^{\prime}} \mathrm{mg} / \mathrm{g}\right)$ or at time $\mathrm{t}\left(q_{p} \mathrm{mg} / \mathrm{g}\right)$ was calculated according to the following expressions :

$$
\begin{aligned}
& q_{e}=\frac{\left(C_{0}-C_{e}\right)}{\mathrm{m}} V \\
& q_{t}=\frac{\left(C_{0}-C_{t}\right)}{\mathrm{m}} V
\end{aligned}
$$

Egypt.J.Chem. 61, No.3 (2018) 
Where $C_{0}, C_{e}$, and $C_{t}$ are concentrations $(\mathrm{mg} / \mathrm{L})$ of $\mathrm{MG}$ dye at initial, equilibrium and time, respectively. $V$ is the volume of solution $(\mathrm{mL})$ and $m$ is the mass of dried adsorbent (mg).

\section{Adsorption models}

Three common kinetic models were used in order to investigate the adsorption mechanism of MG dye onto an adsorbent. Firstly, the Lagergrenfirst-order kinetic model can be described by the equation [28]:

$$
\log \left(q_{e}-q_{t}\right)=\log q_{e}-\frac{k_{1} t}{2.303}
$$

Where $q_{e}$ and $q_{t}$ are the amounts of MG dye adsorbed $(\mathrm{mg} / \mathrm{g})$ at equilibrium and time $\mathrm{t}$ (min), respectively; $k_{1}$ is the rate constant of the Lagergren-first-order kinetic model $\left(\mathrm{min}^{-1}\right)$. The values of $\mathrm{k}_{1}$ were calculated from the plots of $\log$ $\left(\mathrm{q}_{\mathrm{e}}-\mathrm{q}_{\mathrm{t}}\right)$ versus $t$.

Secondly, a linear form of pseudo-secondorder kinetic model was expressed by the equation [29]:

$$
t / q_{t}=\frac{1}{k_{2} q_{e}^{2}}+\frac{t}{q_{e}}
$$

Where $\mathrm{k}_{2}$ is the rate constant $(\mathrm{g} / \mathrm{mg}$ min) of pseudo-second-order kinetic model of adsorption and $k_{2} q_{e}^{2}$ is the initial adsorption rate $(\mathrm{h}, \mathrm{mg} / \mathrm{g}$ min). The slope and intercept of the linear plots $\mathrm{t} / \mathrm{q}_{\mathrm{t}}$ against $t$ yield the values of $1 / \mathrm{q}_{\mathrm{e}}$ and $1 / \mathrm{k}_{2} \mathrm{q}_{\mathrm{e}}{ }^{2}$.

Thirdly, an intra-particle mass transfer diffusion model can be described by the equation [30]:

$$
\mathrm{q}_{\mathrm{t}}=k_{i d} \mathrm{t}^{1 / 2}+C
$$

Where $k_{i d}$ is the intra-particle diffusion rate constant $\left(\mathrm{mg} / \mathrm{g} \mathrm{min}^{1 / 2}\right)$ and $C$ is the intercept, which can be calculated from the slope and intercept of the linear plots of $q_{t}$ versus $t^{1 / 2}$, respectively.

Moreover, the equilibrium adsorption of MG dye onto the prepared adsorbents was analyzed in terms of Langmuir, Freundlich, and Temkin adsorption isotherms. The linear form of the Langmuir isotherm is expressed as the following equation [31]:

$$
\frac{C_{e}}{q_{e}}=\frac{1}{K_{L} q_{m}}+\frac{1}{q_{m}} C_{e}
$$

Where $\mathrm{C}_{\mathrm{e}}$ is the equilibrium concentration of $\mathrm{MG}$ dye $(\mathrm{mg} / \mathrm{L}), \mathrm{q}_{\mathrm{e}}$ the uptake amount of MG dye at equilibrium $(\mathrm{mg} / \mathrm{g})$, and $\mathrm{q}_{\mathrm{m}}$ is the monolayer adsorption capacity $(\mathrm{mg} / \mathrm{g})$ and $K_{L}(\mathrm{~L} / \mathrm{mg})$ is the Langmuir adsorption equilibrium constant. The Gibbs free energy of adsorption, $\Delta G(\mathrm{~kJ} / \mathrm{mol})$ can also be evaluated from the parameter $K_{L}$ according to the expression:

\section{$\Delta \mathrm{G}=-\mathrm{RT} \ln K_{L}$}

Where $R$ is universal gas constant $8.314 \mathrm{~J} / \mathrm{mol}$ $\mathrm{K}$, and $T$ is absolute temperature. In addition, Langmuir adsorption isotherm can be given in an expression of a dimensionless constant called a "separation factor" and noted as $\left(R_{\mathrm{L}}\right)$ :

$$
R_{L}=\frac{1}{1+C_{o} K_{L}}
$$

The equation representing linear form of Freundlich adsorption can be given as [32]:

$$
\ln q_{\mathrm{e}}=\ln K_{\mathrm{F}}+1 / \ln \ln C_{\mathrm{e}}
$$

Where $\mathrm{K}_{\mathrm{F}}\left[(\mathrm{mg} / \mathrm{g}) /(\mathrm{L} / \mathrm{mg})^{1 / \mathrm{n}}\right]$ is roughly an indicator of the adsorption capacity and $1 / \mathrm{n}$ is the adsorption intensity. Freundlich constants $K_{F}$ and $1 / n$ can be calculated from the intercept and slope of the linear plot with $\ln \mathrm{q}_{\mathrm{e}}$ against $\ln \mathrm{C}_{\mathrm{e}}$.

Flory-Huggins isotherm [33] describes the degree of surface coverage characteristics of the adsorbate on the adsorbent. The linear form of the Flory-Huggins equation is expressed as:

$$
\ln \left(\frac{\theta}{C_{0}}\right)=\ln K_{F H}+n_{F H} \ln (1-\theta)
$$

Where $\theta=1-\mathrm{C}_{\mathrm{e}} / \mathrm{C}_{\mathrm{o}}$ is the degree of surface coverage, $n_{\mathrm{FH}}$ is the number of adsorbates occupying adsorption sites, and $K_{\mathrm{FH}}$ is the FloryHuggins equilibrium constant $(\mathrm{L} / \mathrm{mol})$.

\section{$\underline{\text { Results and Discussion }}$}

Surface characteristics of samples

The results of FTIR spectra of the prepared carbon adsorbents are shown in Fig. 3 with their corresponding wavenumbers. FTIR spectra of 
the three prepared samples show two distinct regions to describe the functional oxygen groups, which form the structure of carbon matrix. These regions are located between $3748-2854 \mathrm{~cm}^{-1}$ and $1630-420 \mathrm{~cm}^{-1}$. In the first region, the prominent functional groups are related to $-\mathrm{OH}$ and $\mathrm{C}-\mathrm{H}$ in all samples, respectively. Particularly, the absorption bands at $3442 \mathrm{~cm}^{-1}$ and $3748 \mathrm{~cm}^{-1}$ are corresponded to the stretching vibration of hydrogen bonded $-\mathrm{OH}$ and free- $\mathrm{OH}$ in phenolic, lactonic and carboxylic groups. Appearance of a sharp band at $1630 \mathrm{~cm}^{-1}$ for all samples is ascribed to bending of $-\mathrm{OH}$ or to stretching vibration of $\mathrm{C}=\mathrm{C}$ in the aromatic rings. While upon treatment of AC-S with ammonium persulfate, there is a significant reduction obtained in the intensity of all peaks, whereas an increase in the intensity of a band located at $1031 \mathrm{~cm}^{-1}$ is observed. This absorption band is assigned to the stretching vibration of $\mathrm{C}-\mathrm{O}$ in carboxylate groups [3]. In addition, bands located at region between 1300 and $900 \mathrm{~cm}^{-1}$ are also inferred to the stretching vibration of $\mathrm{C}-\mathrm{O}$ in carboxylic acids, alcohols, esters and ethers [4]. With regard to FTIR of AC-S, the outward show of absorption band at $1747 \mathrm{~cm}^{-1}$ is explained on the basis that the stretching vibration of $\mathrm{C}=\mathrm{O}$ groups in ketones, aldehydes, lactones and carboxylic groups as a result in the action of sulphuric acid activation. After oxidation, this band is not observed and a broadening in the intensity of band located at $1630 \mathrm{~cm}^{-1}$ is occurred. Shoulder bands at 1458$1386 \mathrm{~cm}^{-1}$ conjugated with strong band at 1630 $\mathrm{cm}^{-1}$ may be ascribed to the presence of carboxylic acid, carbonyl-carbonates and quinones, also moieties such as $\mathrm{C}=\mathrm{N}, \mathrm{C}=\mathrm{C}$ and $\mathrm{NH}_{3}$ in aromatic rings [5-11]. Finally, the presence of $\mathrm{C}-\mathrm{H}$ outof-plane bending vibrations in the aromatic ring is identified by the appearance of small bands at $800-420 \mathrm{~cm}^{-1}$.

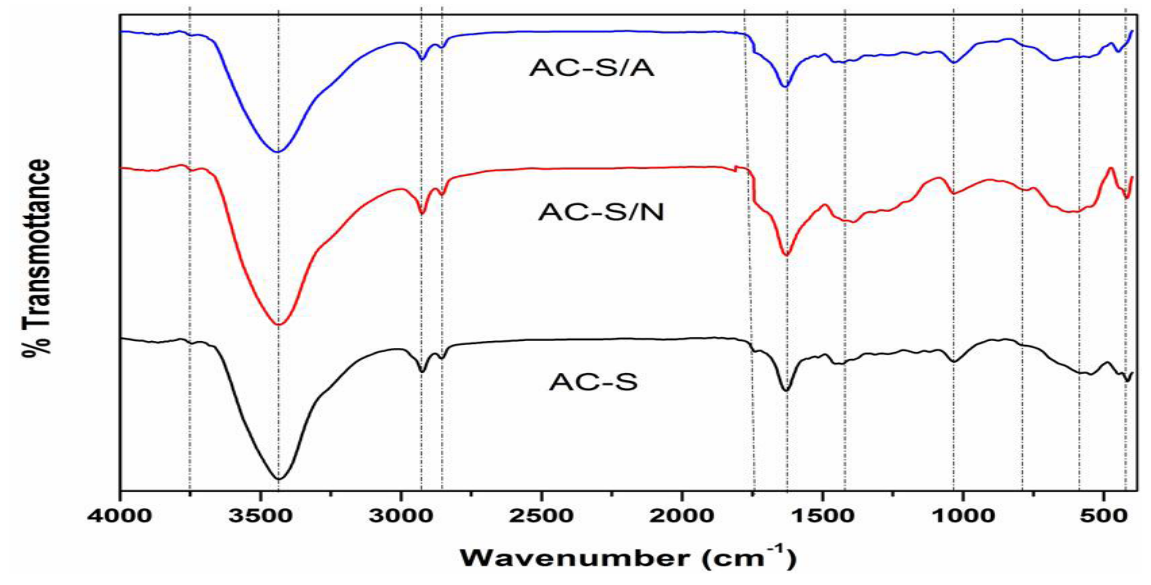

Fig. 3. FTIR spectra of the prepared adsorbents.

Briefly, from the FTIR spectra it can be deduced that most of the acidic oxygen functional sites are developed as a result in the formation of carboxylic, phenolic, carbonyl as well as of nitrogen-containing functional groups. In conclusion, the treated AC-S with nitric acid is rich with higher contents of oxygen and nitrogen-containing surface functional groups than that formed by treating AC-S with ammonium persulfate. Moreover, the presence of such surface functional groups can be evident by the change in the $\mathrm{pH}$-slurry values of the AC-S sample as indicated in Table 1.

TABLE 1. Surface and textural parameters of the prepared samples.

\begin{tabular}{lccc}
\hline \multicolumn{1}{c}{ Parameters } & AC-S & AC-S/N & AC-S/A \\
\hline Slurry $\mathrm{pH}$ & 4.84 & 4.11 & 5.25 \\
Total acidity $(\mathrm{mmol} / \mathrm{g})$ & 0.081 & 0.115 & 0.122 \\
Total basicity $(\mathrm{mmol} / \mathrm{g})$ & 0.041 & 0.037 & 0.060 \\
$\mathrm{~S}_{\mathrm{BET}}\left(\mathrm{m}^{2} / \mathrm{g}\right)$ & 158 & 266 & 225 \\
$\mathrm{~V}_{\mathrm{p}}\left(\mathrm{cm}^{3} / \mathrm{g}\right)$ & 0.184 & 0.225 & 0.192 \\
$\mathrm{~W}_{\mathrm{p}}(\AA)$ & 46.6 & 33.8 & 32.7 \\
\hline
\end{tabular}

Egypt.J.Chem. 61, No.3 (2018) 
The slurry $\mathrm{pH}$ values of the prepared samples show that the surface of them is acidic in nature. Furthermore, Fig. 4 depicts the distribution of acidic and basic groups within the help of potentiometric titration method. In previous studies [8,9], it has been reported that the acidic groups can cover the range of $\mathrm{pH}<4$ whereas, the basic groups concentrated at $\mathrm{pH}>9$. The total amounts of acidic and basic sites in the present samples using potentiometric titration are reported in Table 1. Pronounced changes in the amount of acids and bases can be detected as shown in Fig. 3. The dominant functional groups on the surface are acidic as counted and listed in Table 1. Thus, the oxidation of AC-S with nitric acid and ammonium persulfate results in an increase in the number of acidic groups for AC$\mathrm{S} / \mathrm{N}$ and AC-S/A. For example, the acidity in AC$\mathrm{S} / \mathrm{N}$ and AC-S/A increased from $0.081 \mathrm{mmol} / \mathrm{g}$ to $0.113 \mathrm{mmol} / \mathrm{g}$ (increases about $\sim 40 \%$ ) and 0.122 $\mathrm{mmol} / \mathrm{g}$ (increases about $\sim 51 \%$ ). These results are inconsistent with that obtained from FTIR spectra. Furthermore, the reduction in the basic sites is noticed with $\mathrm{HNO}_{3}$ oxidation ( $\left.\sim 9 \%\right)$ while $\left(\mathrm{NH}_{4}\right)_{2} \mathrm{~S}_{2} \mathrm{O}_{8}$ increased the basicity considerably by $(\sim 25 \%)$. In other words, the ratio of base/ acid is approximately equal to: $1 / 2,1 / 3$ and $1 / 2$ $1 / 2$ in AC-S, AC-S/N and AC-S/A, respectively. Some works pointed out that the basicity of these samples is probably due to oxygen free Lewis basic sites, which are usually ascribed to $\pi$-electrons of graphitic planes [11, 12]. Thus, the obtained carbon from $\mathrm{HNO}_{3}$ oxidation with lower $\mathrm{pH} \sim 4$ seems to be the best acidic carbon because it has the lowest amount of basic oxygen functional groups as compared to AC-S and AC$\mathrm{S} / \mathrm{A}$ samples. This type of carbon is an effective adsorbent for adsorption of cationic dyes from aqueous solutions as shown in the next sections.

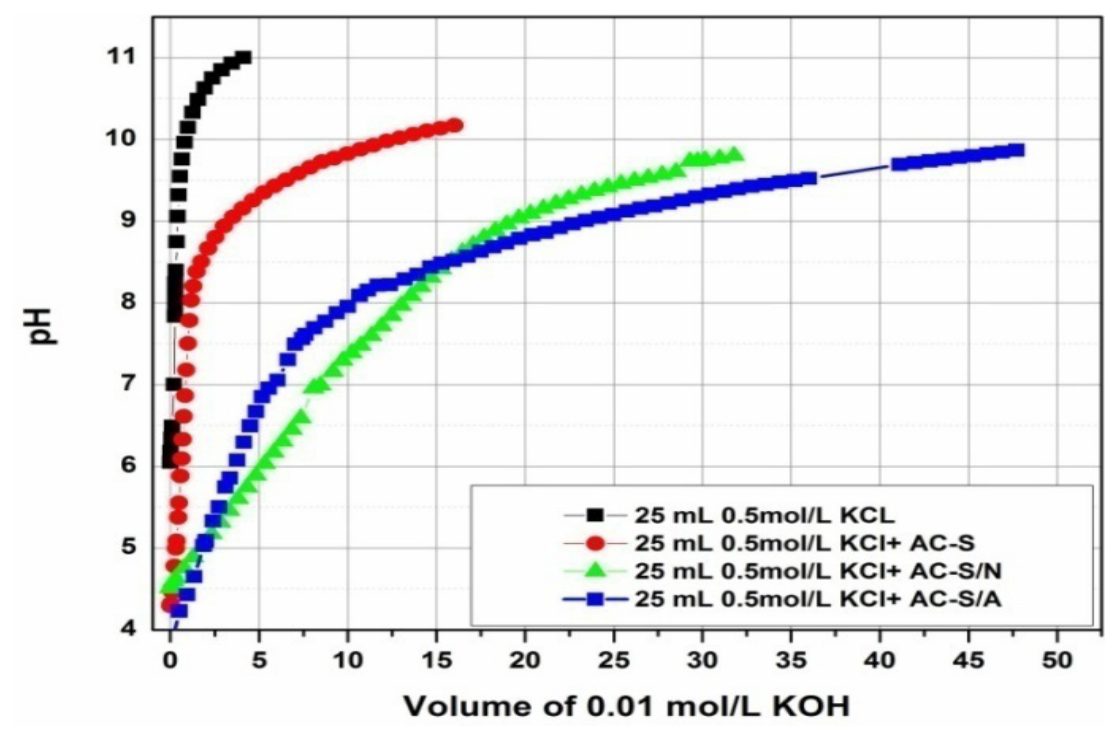

Fig. 4. Potentiometric titrations curves obtained for AC-S, AC-S/N and AC-S/A samples.

Table 1 summarizes the texture properties of the prepared samples (total surface area, total pore volume and pore diameter). The obtained carbon from sulfuric activation exhibits moderate texture properties. Both oxidative reagents $\left(\mathrm{HNO}_{3}\right.$ and $\left.\left(\mathrm{NH}_{4}\right)_{2} \mathrm{~S}_{2} \mathrm{O}_{8}\right)$ increase the total surface area about 68 and $42 \%$ and total pore volume about 22.3 and $4.3 \%$, while pore diameter decreases from $46.6 \AA$ to $32.7 \AA$. From these data, the oxidized carbon with nitric can be acted as an effective adsorbent for removing cationic dye as shown in the next sections.

\section{Effect of $p H$}

The influence of the solution $\mathrm{pH}$ on the adsorption of methyl green onto the activated carbons was performed at constant initial concentration of $150 \mathrm{mg} / \mathrm{L}$ of $\mathrm{MG}$ and the amount of adsorbent $(100 \mathrm{mg})$ under shaking for $4 \mathrm{~h}$ at $200 \mathrm{rpm}$ agitation speed and at $25^{\circ} \mathrm{C}$. The studied range of the $\mathrm{pH}$ was identified between 2 and 9 . Fig. 5 shows the effect of $\mathrm{pH}$ on the adsorption of $\mathrm{MG}$ dye on the studied activated carbons. It appears that the $\mathrm{pH}$ has a great impact on the adsorption behavior of dye. The maximum 
adsorption amount of $\mathrm{MG}$ was achieved at $\mathrm{pH}$ 6. It is well-known that the surface functional groups and slurry or surface $\mathrm{pH}$ of adsorbent (which is similar to $\mathrm{pH}_{\mathrm{pzc}}$, i.e., the $\mathrm{pH}$ at which the net surface charge on the carbon surface was zero) are imperative characteristics for adsorption process, which identify the acidity/basicity of the activated carbon surface (either H- or L-type) and the net surface charge of the carbon in solution [20]. The MG is a cationic dye with $\mathrm{pH} \sim 6$ and gives positively charged ions when dissolved in water. At $\mathrm{pH}_{\text {dye solution }}<\mathrm{pH}_{\mathrm{pzc}}$, the carbon surface has a net positive charge, while at $\mathrm{pH}_{\text {dye solution }}>$
$\mathrm{pH}_{\mathrm{pzc}}$ the surface has a net negative charge [20]. While the surface $\mathrm{pH}$ of samples is lower than $\mathrm{pH}$ of dye solution ( $\mathrm{pH} 6)$, the high electrostatic attraction between $\mathrm{MG}$ cationic dye (+ve charges) and negative charges surrounded surface of acidic carbons was obtained. On the other hand, a decrease in the adsorption of dye was seen at $\mathrm{pH}$ 9. That was due to electrostatic repulsion between the positively charged dye and the positive charges on the surface of activated carbons. Clearly, the adsorption of MG dye was strongly depended on $\mathrm{pH}$. Thus, the further adsorption experiments of MG onto present activated carbons were carried out at $\mathrm{pH} 6$.

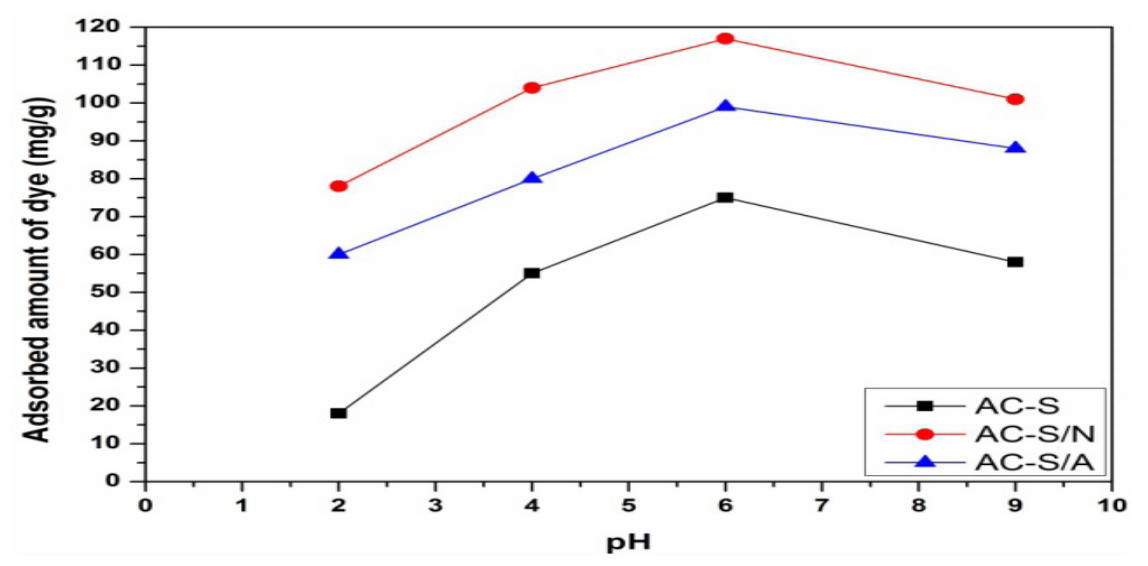

Fig. 5. Effect of $\mathrm{pH}$ on the adsorption of $\mathrm{MG}$ dye $\left(\mathrm{C}_{0}=150 \mathrm{mg} / \mathrm{L}\right.$, adsorbent weight $=100 \mathrm{mg}, \mathrm{pH}=6$ and $\left.\mathrm{T}=25^{\circ} \mathrm{C}\right)$.

\section{Effect of dye concentration}

The impact of initial dye concentration (between 50 and $250 \mathrm{mg} / \mathrm{L}$ ) on the adsorption of $\mathrm{MG}$ on the prepared activated carbons was studied at $\mathrm{pH} 6$ and $25^{\circ} \mathrm{C}$ as shown in Fig. 6 . The adsorption amount ( $\mathrm{mg} / \mathrm{g}$ ) for $\mathrm{MG}$ increased with raising the initial $\mathrm{MG}$ concentration for the activated carbons (AC-S, AC-S/N and AC-S/A).
This result confirms that the prepared activated carbons have the availability of more adsorption sites to uptake dye with high initial concentration that reached $250 \mathrm{mg} / \mathrm{L}$. These adsorption sites related to acidic functional groups provide a powerful driving force to overcome the mass transfer resistance which arising between the aqueous medium and the solid phase.

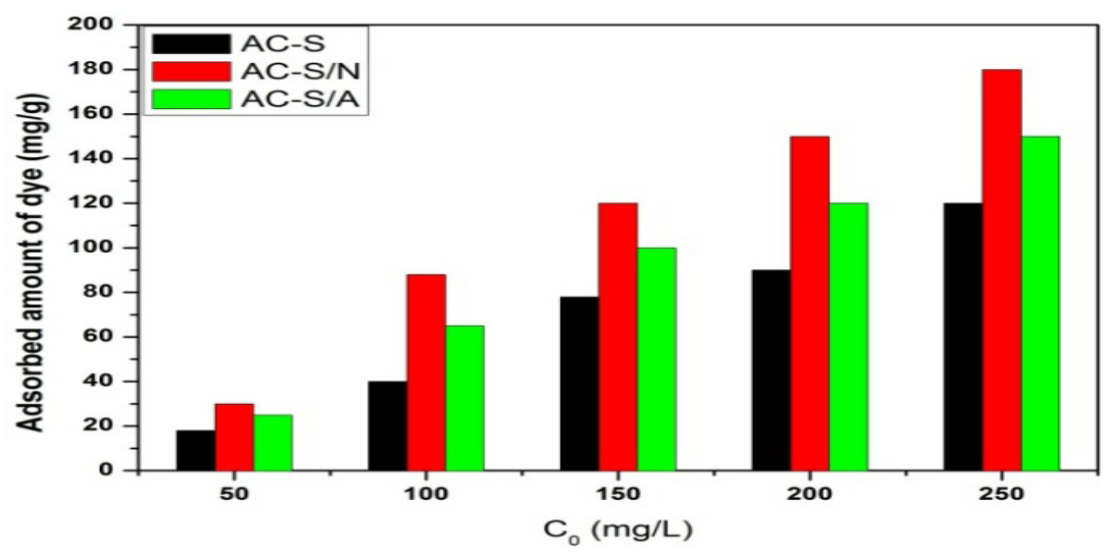

Fig. 6. Effect of initial concentrations on the adsorption of MG dye onto prepared activated carbons (adsorbent weight $=100 \mathrm{mg}, \mathrm{pH}=6$ and $\mathrm{T}=25^{\circ} \mathrm{C}$ ).

Egypt.J.Chem. 61, No.3 (2018) 


\section{Effect of contact time}

Figure 7 reflects the effect of contact time between 10 and $100 \mathrm{~min}$ on the adsorption of 100 $\mathrm{mg} / \mathrm{L} \mathrm{MG}$ dye onto $100 \mathrm{mg}$ of activated carbons at $\mathrm{pH} 6$ and $25^{\circ} \mathrm{C}$. It can be seen from the figure that the adsorption quantity $(\mathrm{mg} / \mathrm{g})$ of MG dye increase rapidly with increasing contact time from 10 to 40 min and then follow up of slow increases slowly over $40 \mathrm{~min}$. Thus, the equilibrium adsorption of MG dye can be obtained after $40 \mathrm{~min}$. It is also important to mention that the rate of adsorption is quite fast during the initial few minutes. The initial faster rate may be due to the availability of uncovered surface area of the adsorbent primarily. This is because the kinetics of the adsorption process was found to be depending on the concentration and the nature of the active sites on the adsorbent surface, which are responsible for the interaction with MG dye.

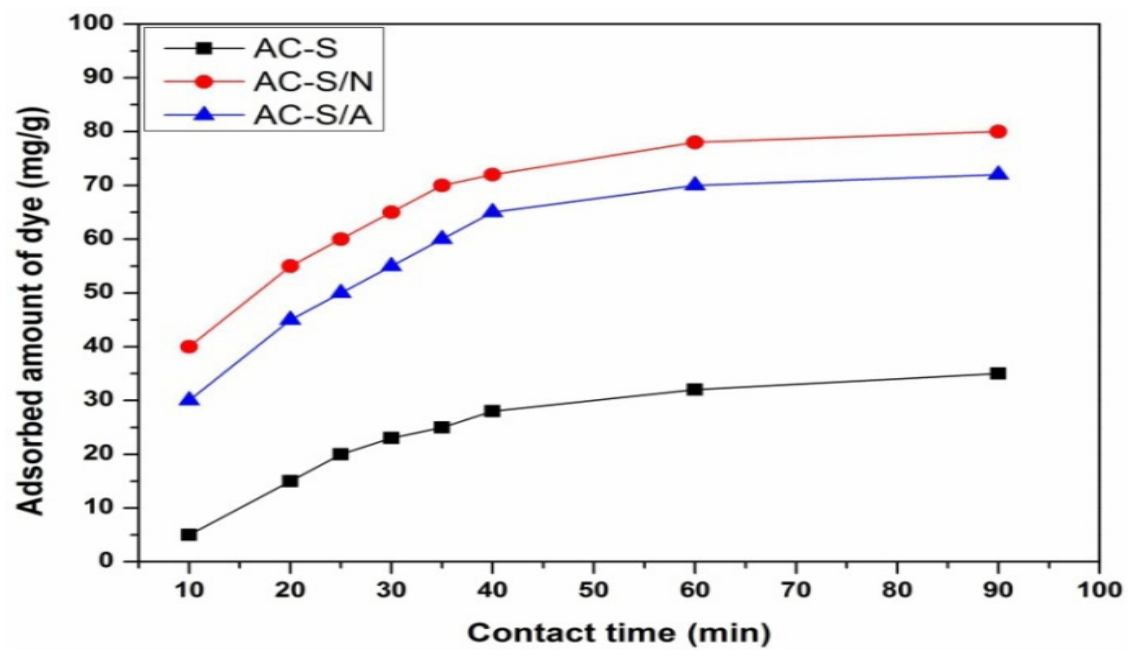

Fig. 7. Influence of contact time on the adsorption of $M G$ dye $\left(C_{0}=100 \mathrm{mg} / \mathrm{L}\right.$, adsorbent weight $=100 \mathrm{mg}, \mathrm{pH}=6$ and $\mathrm{T}=25^{\circ} \mathrm{C}$ ).

\section{Kinetic studies}

The kinetic mechanism, which controls the adsorption process, was assessed using the pseudofirst-order, pseudo-second-order, and intraparticle diffusion to understand the adsorption isotherm data of MG dye onto the present samples. Plots derived from the kinetic models are shown in Fig. 8 and their calculated parameters are summarized in Table 2. By comparing the correlation coefficient $\left(\mathrm{R}^{2}\right)$ values of pseudo-first-order and pseudosecond-order, the $\mathrm{R}^{2}$ values for pseudo-secondorder kinetic model are higher than that of pseudofirst-order for all samples $\left(\mathrm{R}^{2}>0.98\right.$, cf. Table 2). In addition, when compared the experimental $\mathrm{q}_{\mathrm{e}(\exp )}$ values with that calculated $\mathrm{q}_{\mathrm{e}(\mathrm{calc})}$ from the linear plots of pseudo-first-order model and pseudosecond-order model, the experimental $\mathrm{q}_{\mathrm{e}(\exp )}$ values are well-correlated with that calculated $\mathrm{q}_{\mathrm{e}(\mathrm{calc})}$ from pseudo-second-order model. This shows that the kinetic modeling of the MG dye adsorption on the prepared adsorbents will follow the pseudo-second-order rate. The initial adsorption rate parameter $(\mathrm{h}, \mathrm{mg} / \mathrm{g} \mathrm{min})$ indicates that, at the beginning of process, the adsorption of MG dye was faster onto AC-S (1.01 mg/g min) than that obtained over others. This result may be explained on the basis of the high total surface area and total pore volume of the AC-S adsorbent may provide more active sites for removal of MG dye. Furthermore, the rate controlling the adsorption of MG onto the samples can be determined using the intraparticle diffusion step. If intraparticle diffusion is the rate-controlling step, the line will pass through the origin, the intraparticle diffusion (Fig. 8C). However, an intraparticle diffusion plot for adsorption of MG dye onto AC-S shows two straight lines with deviation after $40 \mathrm{~min}$ while adsorption onto AC-S/N and AC-S/A adsorbents exhibits two linear sections with deviation occurs after $60 \mathrm{~min}$. This behavior results in a difference in the mass transfer rate between the initial and the final stages of adsorption [22, 24, 25]. The initial line section represents the surface or film diffusion and the second one is the intraparticle or pore diffusion. Table 2 shows that the correlation coefficient $\left(\mathrm{R}^{2}\right)$ values for intraparticle diffusion model are lower than the pseudo-second-order 
kinetic model. Some other results have been described in a previous study that dealt with the creation or preparation of the activated carbon from various biomasses by $\mathrm{H}_{2} \mathrm{SO}_{4}$ activation $[17,18]$.
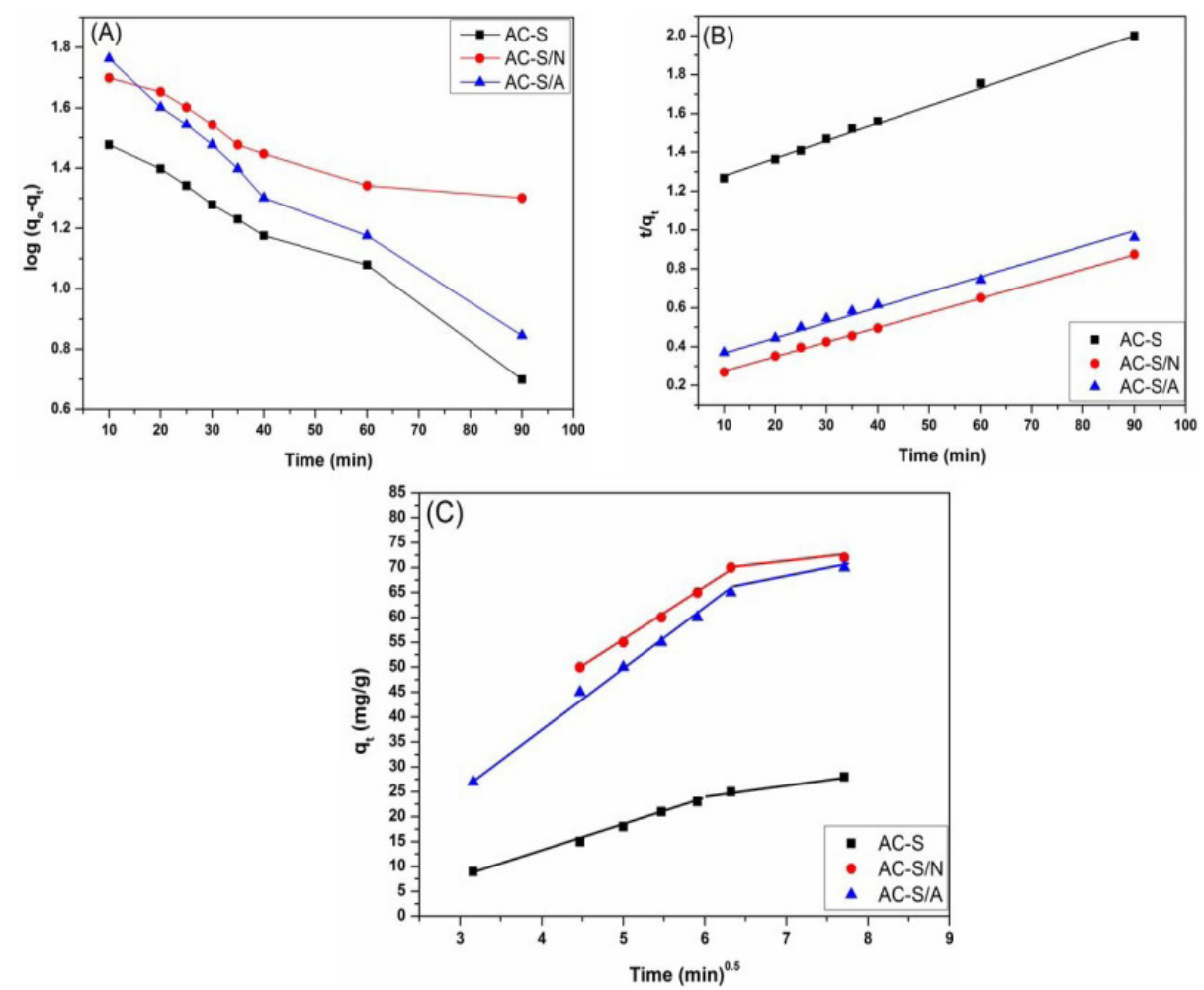

Fig. 8. Plots of (A) pseudo-first-order model, (B) pseudo-second-order model and (C) intraparticle diffusion model $\left(\mathrm{C}_{0}=100 \mathrm{mg} / \mathrm{L}\right.$, adsorbent weight $=100 \mathrm{mg}, \mathrm{pH}=6$ and $\left.\mathrm{T}=25^{\circ} \mathrm{C}\right)$.

TABLE 2. Calculated parameters from Pseudo-first-order, pseudo-second-order kinetic and intraparticle diffusion models for adsorption of $\mathrm{MG}$ dye at $\mathrm{pH} 6$ and $25^{\circ} \mathrm{C}$.

\begin{tabular}{|c|c|c|c|c|c|c|c|c|c|c|c|}
\hline \multirow[t]{2}{*}{ Adsorbents } & \multirow{2}{*}{$\begin{array}{c}\mathrm{C}_{\mathrm{o}}=100 \\
\mathrm{mg} / \mathrm{L}\end{array}$} & \multicolumn{3}{|c|}{ Pseudo-first-order } & \multicolumn{4}{|c|}{ Pseudo-second-order } & \multicolumn{3}{|c|}{ Intraparticle diffusion } \\
\hline & & $\begin{array}{c}\mathbf{k}_{1} \\
\left(\min ^{-1}\right)\end{array}$ & $\begin{array}{c}\mathbf{q}_{\mathbf{e} \text { (cal) }} \\
(\mathrm{mg} / \mathrm{g})\end{array}$ & $\mathbf{R}^{2}$ & $\begin{array}{c}k_{2} \\
(g / m g \\
\mathrm{min})\end{array}$ & $\begin{array}{c}\mathrm{h} \\
(\mathrm{mg} / \mathrm{g} \\
\mathrm{min})\end{array}$ & $\begin{array}{c}\mathrm{q}_{\mathrm{e}(\mathrm{cal})} \\
(\mathrm{mg} / \mathrm{g})\end{array}$ & $\mathbf{R}^{2}$ & $\begin{array}{c}\mathbf{k}_{\mathrm{id}} \\
(\mathrm{mg} / \mathrm{g} \\
\left.\mathrm{min}^{1 / 2}\right)\end{array}$ & C & $\mathbf{R}^{2}$ \\
\hline AC-S & 40 & 0.027 & 71 & 0.947 & $1.95 \times 10^{-4}$ & 1.01 & 45 & 0.988 & 4.99 & 6.84 & 0.957 \\
\hline AC-S/N & 100 & 0.016 & 58 & 0.938 & $7.75 \times 10^{-4}$ & 0.129 & 100 & 0.998 & 6.52 & 28.9 & 0.948 \\
\hline AC-S/A & 85 & 0.034 & 125 & 0.958 & $2.32 \times 10^{-4}$ & 0.276 & 83 & 0.995 & 9.80 & 0.145 & 0.972 \\
\hline
\end{tabular}

\section{Equilibrium adsorption studies}

Figure 9 illustrates the liquid phase adsorption isotherms onto the prepared activated carbons. Two distinct types of isotherms are detected corresponding to the type of adsorbent. It can be observed that the adsorption of MG dye onto AC-S follows S-type isotherm, whereas both AC$\mathrm{S} / \mathrm{N}$ and $\mathrm{AC}-\mathrm{S} / \mathrm{A}$ samples were appeared H-type isotherm according to Giles classification $[34,35]$. The S-curve is usually a result of "cooperative adsorption", with solute molecules tending to be adsorbed packed in rows or clusters [35]. A type $S$ isotherm appears when the binding energy of the first layer is lower than the binding energy between water molecules, affirming the occurrence of physisorption mechanism by Van der Waals interactions between MG dye molecules and AC-S adsorbent. The H-type reflects the strong interactions between adsorbate and adsorbent confirming ionic interactions or chemisorption

Egypt.J.Chem. 61, No.3 (2018) 
mechanism. Therefore, physisorption by an electrostatic attraction of positively charged $\mathrm{MG}$ dye with negatively charged acidic functional groups of AC-S/N and AC-S/A is shown in this study.

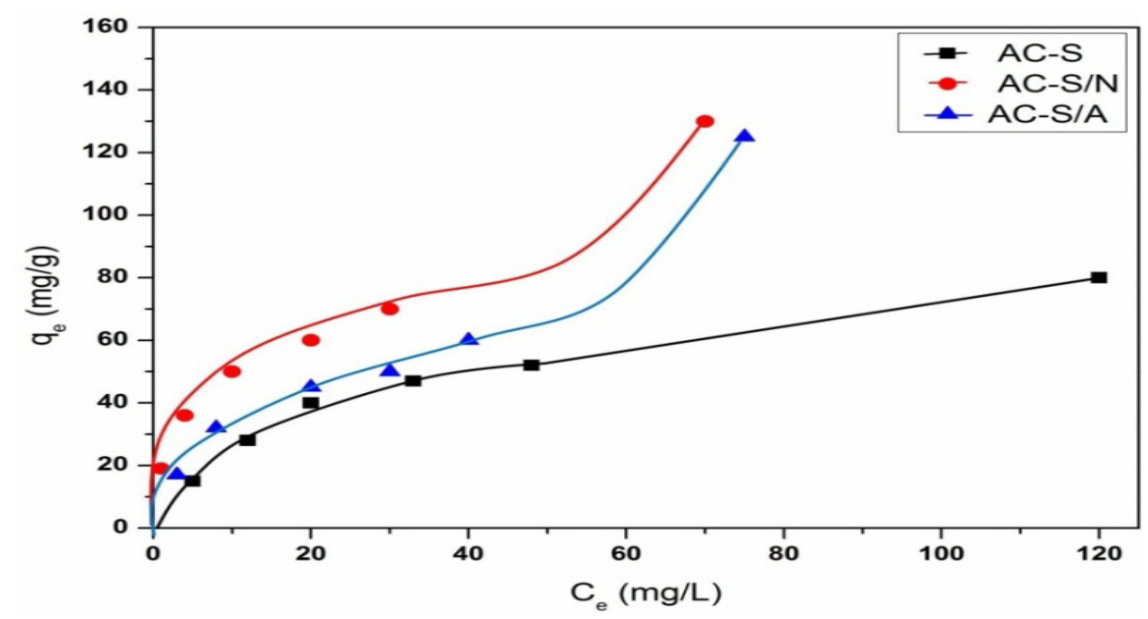

Fig. 9. Liquid phase adsorption of MG dye onto the prepared activated carbons $\left(C_{0}=20-200 \mathrm{mg} / \mathrm{L}\right.$, adsorbent weight $=100 \mathrm{mg}, \mathrm{pH}=6$ and $\mathrm{T}=25^{\circ} \mathrm{C}$ ).

Three isotherms of Langmuir, Freundlich and Florry-Huggins were applied to analyze the adsorption data. Based on the values of linear correlation coefficients $\left(\mathrm{R}^{2}\right)$ obtained from these isotherms, it was found that the best-fit isotherm to adsorption experiments was Langmuir $\left(\mathrm{R}^{2}=\right.$ 0.999-0.970) as compared to others. This result suggests that the adsorption of MG dye onto prepared samples was monolayer adsorption. The monolayer adsorption capacities $\left(\mathrm{q}_{\mathrm{m}}, \mathrm{mg} / \mathrm{g}\right)$ calculated from Langmuir equation (6) were found to be 100, 200 and $125 \mathrm{mg} / \mathrm{g}$ ( $c f$. Table 3) onto AC-S, AC-S/N and AC-S/A, respectively. However, the adsorption data of MG dye shows sequence order for isotherms according $\mathrm{R}^{2}$ as follows: Langmuir $>$ Florry-Huggins $>$ Freundlich as listed in Table 3 . The spontaneous nature of adsorption process is measured by the negative value of Gibbs free energy $(\Delta G, \mathrm{~kJ} / \mathrm{mol})$. Table 3 indicates that the negative values of $\Delta \mathrm{G}$ were almost similar and equal to $-24 \mathrm{~kJ} / \mathrm{mol}$. This result assures the feasibility adsorption of $\mathrm{MG}$ dye onto the prepared samples. Bahgat et al. [23] recently studied the adsorption of methyl green dye onto multi-walled carbon nanotubes (CNTs) and its counterpart decorated with nickel ferrite $\left(\mathrm{NiFe}_{2} \mathrm{O}_{4}\right.$-CNTs). They found that the adsorption data were well fitted with Langmuir, and the maximum monolayer adsorption capacities were 146 and $88 \mathrm{mg} / \mathrm{g}$ onto CNTs and $\mathrm{NiFe}_{2} \mathrm{O}_{4}$-CNTs at $25^{\circ} \mathrm{C}$, respectively. Thus, the prepared samples from natural plant understudied conditions exhibit higher capacities that reached $200 \mathrm{mg} / \mathrm{g}$ as compared to those samples.

TABLE 3. Calculated parameters from Langmuir, Freundlich, and Florry-Higgins isotherms for adsorption of MG dye onto the prepared materials at $\mathrm{pH} 6$ and $25^{\circ} \mathrm{C}$.

\begin{tabular}{cccc}
\hline Models & AC-S & AC-S/N & AC-S/A \\
\hline Langmuir & & & 125 \\
$q_{m}(m g / g)$ & 100 & 200 & 0.0315 \\
$K_{L}(L / m g)$ & 0.0294 & 0.0344 & 0.1370 \\
$R_{L}$ & 0.1453 & 0.1269 & -24.6 \\
$\Delta G(k J / m o l)$ & -24.4 & -24.8 & 0.970 \\
$R^{2}$ & 0.999 & 0.988 & 10.1 \\
Freundlich & & & 0.875 \\
$K_{F}\left((m g / g) /(L / m g)^{1 / n}\right)$ & 26.2 & 14.1 & 0.887 \\
$1 / n$ & 0.326 & 0.506 & 2.03 \\
$R^{2}$ & 0.954 & 0.889 & $5.22 \times 10^{-4}$ \\
Florry-Huggins $_{\mathrm{n}_{\mathrm{FH}}}$ & 0.599 & 1.63 & 0.935 \\
$\mathrm{~K}_{\mathrm{FH}}(\mathrm{L} / \mathrm{mol})$ & $1.20 \times 10^{-3}$ & $8.32 \times 10^{-4}$ & 0.966 \\
$\mathrm{R}^{2}$ & 0.952 & &
\end{tabular}




\section{Conclusions}

Activated carbons prepared from sulfuric acid activation of belladonna (AC-S) were oxidized chemically with oxidizing agents $\mathrm{HNO}_{3}$ and $\mathrm{NH}_{4} \mathrm{~S}_{2} \mathrm{O}_{8}$ to give AC-S/N and AC-S/A. The resulting samples were characterized by FTIR, potentiometric titration and $\mathrm{N}_{2}$ adsorption. The adsorption properties of these carbons were estimated using methyl green dye as a cationic dye. Acidic carbon adsorbents were obtained with large content of acidic surface functional groups in the sequence order $\mathrm{AC}-\mathrm{S}<\mathrm{AC}-\mathrm{S} / \mathrm{N}<\mathrm{AC}-\mathrm{S} / \mathrm{A}$ as confirmed by FTIR and potentiometric plots. However, a large amount of basic functional groups were found after oxidation with ammonium persulfate $(\mathrm{AC}-\mathrm{S} / \mathrm{N})$ which led to a decrease in its adsorption capacity towards MG dye. the oxidized carbon with nitric yielded high porosity development with surface area of $266 \mathrm{~m}^{2} / \mathrm{g}$. High adsorption capacities were computed and found to be 100,200 and $125 \mathrm{mg} / \mathrm{g}$ from MG dye onto AC$\mathrm{S}, \mathrm{AC}-\mathrm{S} / \mathrm{N}$ and $\mathrm{AC}-\mathrm{S} / \mathrm{A}$, respectively.

The adsorption results illustrate that the adsorption process was $\mathrm{pH}$ dependent with a high adsorption at $\mathrm{pH}$ of 6 which is obviously $\mathrm{pH}$ of dye solution.

The pseudo-second-order kinetic model provided the best fit to the experimental data for the adsorption of MG by the prepared carbons. Yet, the adsorption of MG was more proper and suitable to be controlled by an intraparticle diffusion mechanism. Langmuir, Freundlich and Florry-Huggins isotherm models examined and analyzed the equilibrium adsorption data. The adsorption process was found to be spontaneous and feasible in nature.

\section{Acknowledgment}

The authors gratefully acknowledge the financial support provided by the National Research Centre (NRC), Egypt, under the Project No. 11090201.

\section{References}

1. Bansal, R.C., Donnet, J.B., and Stoeckli,F., "Active Carbons", Marcel Dekker, Inc. New York and Basal (1988).

2. Bandosz,T. J., Ania, C.O., Surface chemistry of activated carbons and its characterization, In: Activated Carbon Surfaces in Environmental Remediation, Bandosz, T.J. (editor), Elsevier Ltd., pp. 186-193 (2006).

Egypt.J.Chem. 61, No.3 (2018)
3. El-Hendawy A. A., Influence of $\mathrm{HNO}_{3}$ oxidation on the structure and adsorptive properties of corncob-based activated carbon, Carbon, 41,713722 (2003).

4. Wafaa E. Rashwan, Badie S. Girgis; Adsorption capacities of activated carbons derived from rice straw and water hyacinth in the removal of organic pollutants from water; Adsorption Science and Technology 22 (3), 181-194 (2004).

5. Fathy, N. A. and El-Sherif, I. Y., Equilibrium removal of $\mathrm{Pb}$ (II) ions from aqueous solution onto oxidized-KOH-activated carbons, Carbon Letters, 12, 1-7 (2011).

6. Girgis, B. S., Elkady, A.A., Attia, A. A., Fathy N. A., and Abd El-Wahhab M. A., Impact of air convection on $\mathrm{H}_{3} \mathrm{PO}_{4}$ - activated biomass for Sequestration of $\mathrm{Cu}$ (II) and Cd (II) ions, Carbon Letters, 10, 114-122 (2009).

7. Chen, J.P. and Wu, S., Acid/base-treated activated carbons: characterization of functional groups and metal adsorptive properties, Langmuir 20, 2233 2242 (2004).

8. Bashkova, S., Bandosz, T.J., The effects of urea modification and heat treatment on the process of $\mathrm{NO}_{2}$ removal by wood-based activated carbon. $J$ Colloid Interface Sci 333, 97-103 (2009).

9. Biniak, S., Szymanski, G., Siedlewski, J., Swiatkowski, A., The characterization of activated carbons with oxygen and nitrogen surface groups, Carbon 35, 1799-1810 (1997).

10. de Mesquita, J. P., Martelli, P. B. and de Fátima Gorgulho, H., Characterization of Copper Adsorption on Oxidized Activated Carbon, $J$. Braz. Chem. Soc. 17, 1133-1143 (2006).

11. Salame, I. I. and Bandosz, T. J., Surface Chemistry of Activated Carbons: Combining the Results of Temperature-Programmed Desorption, Boehm, and Potentiometric Titrations, J. Colloid Interface Science 240, 252-258 (2001).

12. Khelifi, A., Almazán-Almazán, M.C., PérezMendoza, M., Domingo-García, M., LópezDomingo, F.J., Temdrara, L., López-Garzón, F.J, Addoun, A., Influence of nitric acid concentration on the characteristics of active carbons obtained from a mineral coal, Fuel Proc. Technol. 91, 13381344 (2010).

13. Al-Degs, Y., Khraisheh, M., Allen, S., Ahmad, M., Effect of carbon surface chemistry on the removal of reactive dyes from textile effluents. Water Research; 34, 927-935 (2000). 
14. Boehm, H.P., Surface oxides on carbon and their analysis: A critical assessment, Carbon 40, 145149 (2002).

15. Fuente, E., Menéndez, J.A., Suàrez, D. and Montes-Moràn, M.A., Basic Surface Oxides on Carbon Materials: A Global View, Langrnuir 19, 3505-3511 (2003).

16. Aguilar, K. M. M., Amano, Y., Machida, M., Ammonium persulfate oxidized activated carbon fiber as a high capacity adsorbent for aqueous $\mathrm{Pb}(\mathrm{II})$, Journal of Environmental Chemical Engineering 4, 4644-4652 (2016).

17. Gercel, O., Ozcan, A., Ozcan, A.S., Gercel, H.F., Preparation of activated carbon from a renewable bio-plant of Euphorbia Rigida by $\mathrm{H}_{2} \mathrm{SO}_{4}$ activation and its adsorption behavior in aqueous solutions. Appl. Surface Sci. 253, 4843-4852 (2007).

18. Karagoz, S., Tay, T., Ucar, S., Erdem, M., Activated carbons from waste biomass by sulfuric acid activation and their use on methylene blue adsorption, Bioresource Technology 99, 62146222 (2008).

19. Lee M.R., Solanaceae I, V., Atropa belladonna, deadly nightshade. $J \quad R \quad$ Coll Physicians Edinb. 2007 Mar; 37 (1), 77-84. [PubMed] (2007).

20. Robinson, T., McMullan, G., Marchant, R., Nigam, P., Remediation of dyes in textile effluent: a critical review on current treatment technologies with a proposed alternative. Bioresource Technology; 77, 247-55 (2001).

21. Netpradit, S., Thiravetyan, P., Towprayoon, S., Adsorption of three azo reactive dyes by metal hydroxide sludge: effect of temperature, $\mathrm{pH}$, and electrolytes. Journal of Colloid and Interface Science; 270, 255-61 (2004).

22. Tan, I.A.W., Ahmad, A.L. and Hameed, B.H., Adsorption of basic dye on high-surface area activated carbon prepared from coconut husk: equilibrium, kinetic and thermodynamic studies, J. Hazard. Mater. 154, 337-346 (2008).

23. Bahgat, M., Farghali, A. A., El Rouby, W., Khedr, M., Mohassab-Ahmed, M. Y., Adsorption of methyl green dye onto multi-walled carbon nanotubes decorated with Ni nanoferrite, Appl Nanosci 3, 251-261 (2013).
24. Sharma, P., Kaur, R., Baskar, C. and Chung, W.-J., Removal of methylene blue from aqueous waste using rice husk and rice husk ash, Desalination 259, 249-257 (2010).

25. Rodríguez, A., García, J., Ovejero, G. and Mestanza, M., Adsorption of anionic and cationic dyes on activated carbon from aqueous solutions: Equilibrium and kinetics, J. Hazard. Materials 172, 1311-1320 (2009).

26. IUPAC in Recommendations for the characterization of porous solids (Technical Reports), Pure Appl. Chem. 66, 1739 (1994).

27. Selles-Perez, M.J., Martin-Martinez, J.M., Application of $\alpha$ and $\mathrm{n}$ plots to $\mathrm{N}_{2}$ adsorption isotherms of activated carbons. J. Chem. Soc. Faraday Trans.; 87, 1237-43 ( 1991).

28. Lagergren, S., Zur theorie der sogenannten adsorption geloster stoffe. Kungliga Svenska Vetenskapsakademiens, Handlingar 24, 1-39 (1898).

29. Ho, Y.S. and McKay, G., Sorption of dye from aqueous solution by peat, Chem. Eng. J. 70, 115124 (1998).

30. Weber, W.J. and Morris, J.C., Kinetics of adsorption on carbon from solution, J. Sanit. Eng. Div. Am. Soc. Civ. Eng. 89, 31-60 (1963).

31. Langmuir, I., The adsorption of gases on plane surfaces of glass, mica and platinum, J. Am. Chem. Soc. 40, 1361-1403 (1918).

32. Freundlich, H.M.F., Over the adsorption in solution, J. Phys. Chem. 57, 385-470 (1906).

33. Nikitas, P., Generalized Flory-Huggins isotherms for adsorption from solution, J. Chem. Soc. Faraday Trans. 1, 3315-3329 (1984).

34. Giles, C.H., Mac Ewan, T.H., Nakhwa, S. N., Smith, D. Studies in adsorption. Part XI. A system of classification of solution adsorption isotherms, and its use in diagnosis of adsorption mechanisms and in measurement of specific surface areas of solids, J. Chem. Soc. 111, 3973-3993 (1960).

35. Giles, C.H., D'Silva, A.P., Easton, I.A., Ageneral treatment and classification of the solute adsorption isotherm. II. Experimental interpretation, $J$. Colloid Interface Sci. 47, 766-778 (1974).

(Received 4/3/2018; accepted 13/5/2018) 


\title{
تأثير الاكسدة الكيميائية على الخواص الامتزازية لصبغة المثيل الأخضر على كربون منشط محضر من نبات البلادونا

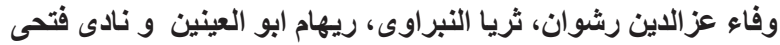

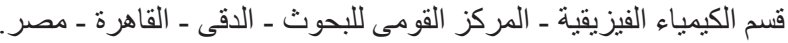

\begin{abstract}
تبحث هذه الدر اسة فى معرفة تأثير الأكسدة الكيميائية الرطبة باستعمال حمض النتريك أو الامونيوم بيرسلفات

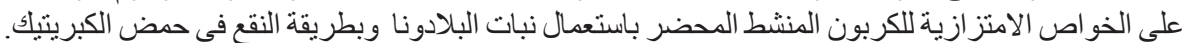

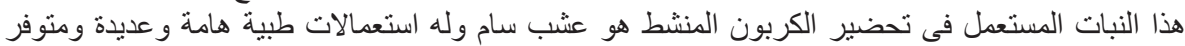

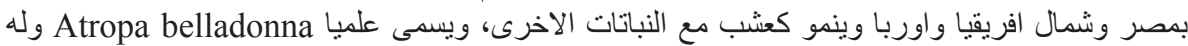

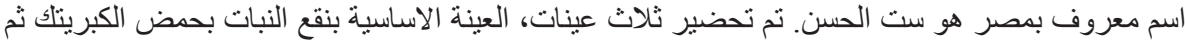

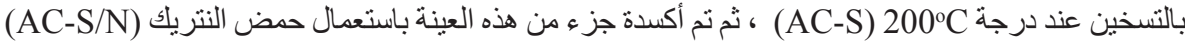
وجزء أخر باستعمال الامونيوم بير سلفات (AC-S/A). تم توصيف الخواص السطحية للكربون و العينات

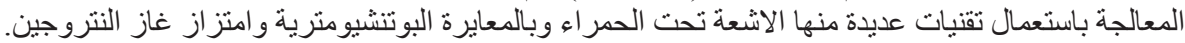

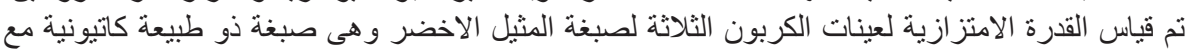

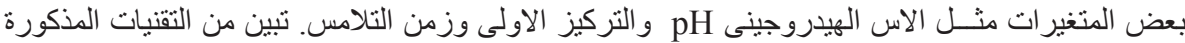

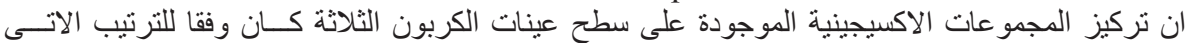
AC-S<AC-S/N<AC-S/A

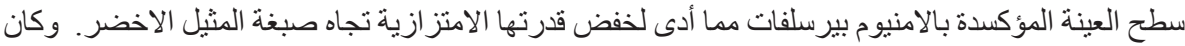
AC-S/N ترتيب القدرة الامتزازية للعينات تجاه صبغة المثنيل الاخضر كالاتى

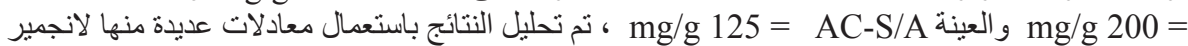

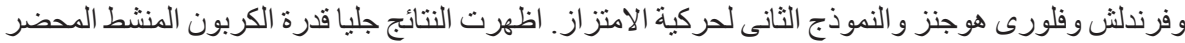

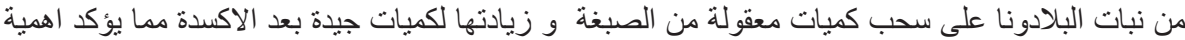
وفعالية عملية المعالجة والاكسدة.
\end{abstract}

